\title{
Alimentación Saludable: El calcio ${ }^{1}$
}

\author{
Linda B. Bobroff²
}

\section{¿Qué es el calcio?}

El calcio es el mineral principal que se encuentra en nuestros huesos y dientes. Nosotros necesitamos calcio para el buen funcionamiento de los músculos y los nervios. El calcio también ayuda en la coagulación de la sangre.

El calcio es un nutriente importante en cada etapa de la vida. Nosotros absorbemos mejor el calcio en los huesos para hacerlos fuertes en las primeras etapas de nuestra vida. A medida que envejecemos, es importante obtener suficiente calcio para evitar pérdida ósea. La vitamina $\mathrm{D}$ ayuda a absorber el calcio, por lo cual es importante consumir suficiente de este nutriente a lo largo de nuestras vidas.

Una gran cantidad de personas mayores no obtienen suficiente calcio de los alimentos que consumen. Esto puede llevar a una enfermedad de los huesos llamada osteoporosis. Las personas con osteoporosis están en alto riesgo de sufrir fracturas en los huesos.

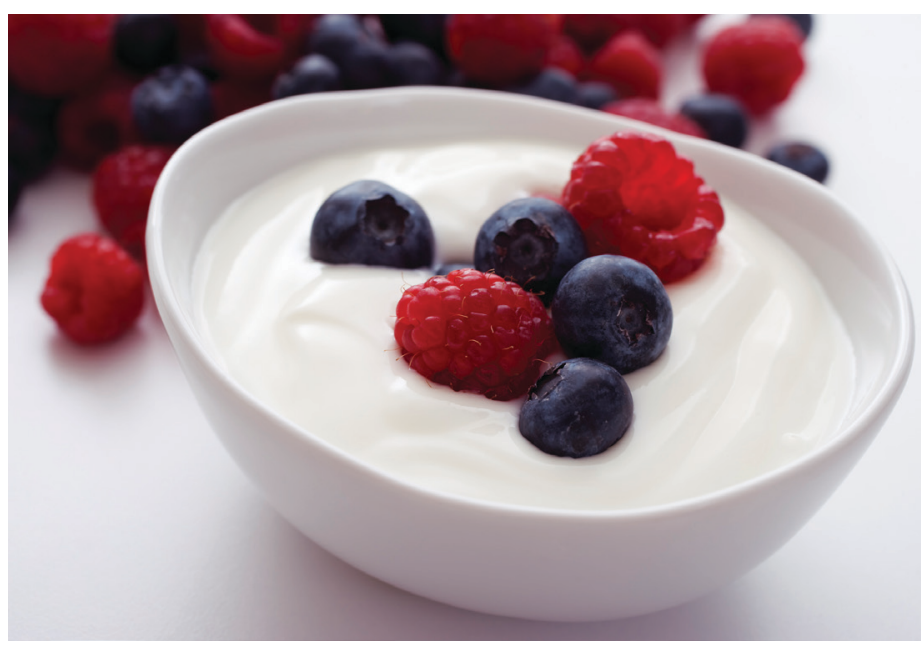

Figure 1. El yogur es una buena fuente de calcio. Credits: LOVE_LIFE / iStock / Getty Images Plus

\section{¿Qué alimentos contienen calcio?}

En los Estados Unidos, la fuente más importante de calcio una para gran cantidad de personas son los productos lácteos. Esto incluye la leche, el yogur, el queso y el helado.

1. Este documento, FCS8568-Span (the English version of this document is Healthy Eating: Calcium (FCS8561)), es uno de una serie de publicaciones del Departamento de Ciencias de la Familia, la Juventud y la Comunidad, Servicio de Extensión Cooperativa de la Florida, Instituto de Alimentos y Ciencias Agrícolas, Universidad de la Florida (UF/IFAS Extension). Fecha de primera publicación: septiembre 1999. Revisado enero 2018. Visite nuestro sitio web EDIS en <http://edis.ifas.ufl.edu>. Este documento fue desarrollado con los fondos de la Florida del Departamento de Asuntos de Mayores, en cooperación con agencias estatales, agencias locales y agencias del condado.

2. Linda B. Bobroff, PhD, RDN, profesora, Departamento de Ciencias de la Familia, la Juventud y la Comunidad; Instituto de Ciencias de Alimentos y Ciencias Agrícolas, Universidad de la Florida (UF/IFAS Extension), Gainesville, FL 32611. 
Los productos lácteos sin o bajos en grasa son recomendados para la salud del corazón.

Muchos vegetales verdes también son buenas fuentes de calcio. La col rizada, lechuga romana y el brócoli proveen calcio. La espinaca contiene varios nutrientes, incluyendo el calcio, pero el ácido oxálico de este vegetal verde previene que el calcio entre en nuestros cuerpos.

Otras fuentes de calcio son las legumbres (como los frijoles rojos, pintos y negros y las lentejas), el queso de soya o tofu (procesado con calcio) y las nueces. Actualmente muchos alimentos son fortificados con calcio. ¡Usted ahora puede consumir calcio en un jugo de naranja!

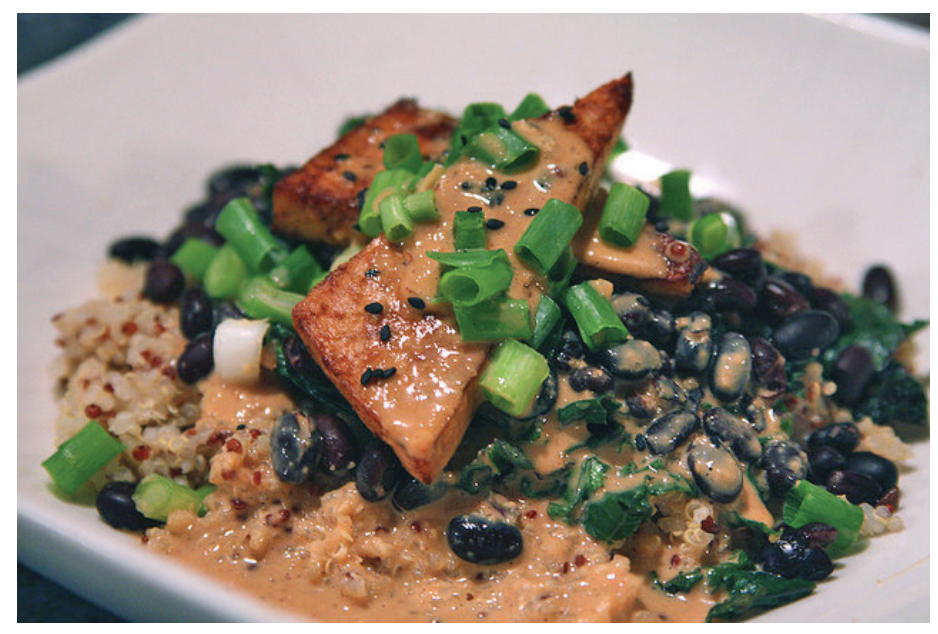

Figure 2. El queso de soya o tofu, la col rizada y los frijoles negros son todas fuentes de calcio.

Credits: Nora Kuby. Usada bajo las licencias Creative Commons (CC) BY-NC-SA 2.0. Fuente: http://ic.kr/p/6Dd3M8

\section{¿Qué pasa si no consumimos suficiente calcio?}

Ya que este es necesario para tantas funciones del cuerpo, nuestro cuerpo posee hormonas que controlan los niveles de calcio en la sangre. Cuando usted no consume suficiente calcio, la hormona paratiroidea (PTH) hace que el calcio sea extraído de nuestros huesos para mantener el calcio en la sangre a un nivel normal.

Con el tiempo, si usted no consume suficiente calcio, sus huesos comenzarán a volverse porosos y débiles. A medida que la pérdida de hueso se vuelva severa, usted puede desarrollar la enfermedad de los huesos llamada osteoporosis. Su doctor puede ordenar un examen de densidad ósea para confirmar si tiene osteoporosis.

\section{¿Qué son las hormonas?}

Las hormonas son mensajeros químicos. Estas son creadas en una parte del cuerpo y luego viajan a otro órgano o tejido. Una vez ahí, las hormonas afectan procesos específicos del cuerpo.

\section{¿Cuánto calcio necesito?}

El consumo recomendado para hombres de 19-70 años y mujeres de 19-50 años de edad es de 1,000 miligramos de calcio al día. $\mathrm{Mu}$ jeres mayores de 51 años y hombres mayores de 70 años de edad deberían intentar consumir 1,200 miligramos de calcio al día. Esto es más de lo que la mayoría de las personas obtienen de los alimentos que consumen. Algunas personas pueden necesitar más calcio para disminuir el riesgo de la osteoporosis. Pregúntele a su proveedor de salud cuánto calcio debe consumir diariamente.

Para obtener el calcio que usted necesita, consuma alimentos que sean naturalmente altos en calcio, como también alimentos con calcio añadido. Si piensa que usted no está consumiendo lo suficiente de este mineral revise la lista de alimentos con calcio y elija uno o dos para introducir en su dieta. Hable con su médico o proveedor de salud antes de decidir tomar suplementos de calcio. 


\section{¿Dónde puedo obtener más información confiable?}

El agente de Ciencias del Consumidor y de las Familias (FCS) en la oficina de Extensión en su condado puede encontrar más información escrita y clases de nutrición a las cuales puede asistir. Un dietista registrado (RD) también puede ofrecerle información confiable.

Llame a la Agencia del Envejecimiento para información sobre programas de alimentación que ofrezcan en su área.

También puede encontrar información nutricional confiable en el Internet en las siguientes páginas electrónicas:

- http://www.nutrition.gov/

- https://www.nof.org/preventing-fractures/ prevention/prevention-and-healthy-living/

- https://medlineplus.gov/osteoporosis.html

- http://www.ChooseMyPlate.gov 
Tabla 1. Contenido de calcio en alimentos seleccionados.

\begin{tabular}{|l|c|}
\hline \multicolumn{1}{|c|}{ Alimento } & Calcio (mg/porción) ${ }^{*}$ \\
\hline Yogur, bajo en grasa, fruta, 1 taza & 345 \\
\hline Leche, baja en grasa, 1 taza & 305 \\
\hline Queso de soya o tofu, crudo, firme, $1 / 2$ taza & 250 \\
\hline Jugo de Naranja con calcio, $3 / 4$ taza & 200 \\
\hline Queso cheddar, bajo en grasa, $1 \frac{1}{2}$ onzas & 120 \\
\hline Col rizada, congelada, cocida, $1 / 2$ taza & 90 \\
\hline Frijoles negros, cocidos, $1 / 2$ taza & 50 \\
\hline Brócoli, cocido, $1 / 2$ taza & 50 \\
\hline Frijoles rojos, cocidos, $1 / 2$ taza & 30 \\
\hline *mg=miligramos & \\
\hline
\end{tabular}

